\title{
DINÂMICA FAMILIAR DE MULHERES COM VÍRUS LINFOTRÓPICO T HUMANO
}

\section{FAMILY DYNAMICS OF WOMEN WITH HUMAN T-LYMPHOTROPIC VIRUS}

\section{LA DINÁMICA FAMILIAR DE LAS MUJERES CON EL VIRUS LINFOTRÓPICO T HUMANO}

\author{
Elaine de Araújo Dias ${ }^{1}$ \\ Daniela Carneiro Sampaio ${ }^{2}$ \\ Maria da Conceição Costa Rivemales ${ }^{3}$ \\ Lavinya Lima Cordeiro Oliveira ${ }^{4}$ \\ Claudia Feio de Maia Lima ${ }^{5}$ \\ George Mariane Soares Santana ${ }^{6}$
}

Como citar este artigo: Dias EA, Sampaio DC, Rivemales MCC, Oliveira LLC, Lima CFM, Santana GMS. Dinâmica familiar de mulheres com Vírus Linfotrópico T Humano. Rev baiana enferm. 2019;33:e33675.

Objetivo: descrever a dinâmica familiar de mulheres soropositivas para o Vírus Linfotrópico T Humano. Método: estudo de caso com consulta de prontuários e entrevista semiestruturada domiciliar, entre outubro e dezembro de 2017, no Recôncavo baiano, Brasil. A análise dos dados subsidiou a construção do genograma e ecomapa. Resultados: a composição familiar está retratada no genograma e o ecomapa representou as diferentes relações; identificados os laços de afetividade. Os dados analisados convergem sobre a descoberta da soropositividade durante o pré-natal; o estabelecimento de relações superficiais com o Centro de Testagem e Aconselhamento; o contágio de uma patologia sexualmente transmissível; questões de relações interpessoais com a família; a negação da soropositividade e a omissão quanto às ações de cuidado. Conclusão: o estudo sobre a dinâmica familiar de mulheres soropositivas para o Vírus Linfotrópico T Humano mostrou que seus potenciais de cuidado precisam ser renovados.

Descritores: Vírus 1 Linfotrópico T Humano. Vírus 2 Linfotrópico T Humano. Relações Familiares. Cuidado de Enfermagem. Vírus HTLV.

Objective: to describe the family dynamics of women seropositive for the Human T-Lymphotropic Virus. Method: case study with consultation of medical records and interviews during home visits, between October and December of 2017, in Recôncavo Baiano, Brazil. The analysis of the data subsidized the construction of the genogram and ecomap. Results: the family composition is depicted in the genogram and the ecomap represented the different relations; the bonds of affection were identified. The data analyzed converge on the discovery of their seropositivity during prenatal care; the establishment of superficial relations with the Testing and Counseling Center; the contagion

\footnotetext{
Enfermeira. Especialista em Gestão em Saúde. Enfermeira da Estratégia Saúde da Família do Alto Sobradinho. Santo Antônio de Jesus, Bahia, Brasil. https://orcid. org/0000-000 I-8407-0804

Bacharela em Saúde. Estudante de Enfermagem. Universidade Federal do Recôncavo da Bahia. Santo Antônio de Jesus, Bahia, Brasil. daniela sampaio1305@hotmail.com.https://orcid.org/0000-0002-0758-0।89

3 Enfermeira. Doutora em Enfermagem. Professora da Universidade Federal do Recôncavo da Bahia. Santo Antônio de Jesus, Bahia, Brasil. https://orcid.org/0000$0001-7773-4772$

${ }^{4}$ Bacharela em Saúde. Estudante de Enfermagem. Universidade Federal do Recôncavo da Bahia. Santo Antônio de Jesus, Bahia, Brasil. https://orcid.org/0000-00032478-4869

5 Enfermeira. Doutora em Enfermagem. Professora da Universidade Federal do Recôncavo da Bahia. Santo Antônio de Jesus, Bahia, Brasil. https://orcid.org/00000002-47| 8-8683

Biólogo. Doutor em Patologia Humana. Professor da Universidade Federal do Recôncavo da Bahia. Santo Antônio de Jesus, Bahia, Brasil. https://orcid.org/00000003-2648-5942
} 
of a sexually transmitted disease; questions of interpersonal relations with the family; the denial of seropositivity and the omission regarding care actions. Conclusion: the study on the family dynamics of women seropositive for the Human T-Lymphotropic Virus showed that their care potential requires renovation.

Descriptors: Human T-Lymphotropic Virus 1. Human T-Lymphotropic Virus 2. Family Relations. Nursing care. HTLV Virus.

Objetivo: describir la dinámica de la familia de las mujeres seropositivas para el Virus Linfotrópico THumano. Método: un estudio de caso con la consulta de los registros médicos y entrevistas durante las visitas domiciliarias, entre octubre $y$ diciembre de 2017, en el Recôncavo Baiano, Brasil. El análisis de los datos subsidió la construcción del genograma y ecomapa. Resultados: la composición familiar está representada en el genograma y el ecomapa representó las distintas relaciones; identificados los lazos de afecto. Los datos analizados convergen en el descubrimiento de su seropositividad durante el control prenatal; el establecimiento de relaciones superficiales con el Centro de Asesoría y Pruebas; el contagio de una enfermedad de transmisión sexual; las cuestiones de relaciones interpersonales con la familia; la negación de la seropositividad y la omisión en relación con acciones de cuidado. Conclusión: el estudio de la dinámica de la familia de las mujeres seropositivas para el Virus Linfotrópico T Humano demostró que su potencial de atención necesita ser renovado.

Descriptores: Virus Linfotrópico T Tipo 1 Humano. Virus Linfotrópico T Tipo 2 Humano. Relaciones Familiares. Atención de Enfermería. Virus HTLV.

\section{Introdução}

A infecção pelo Vírus Linfotrópico T Humano (HTLV) encontra-se presente em todas as regiões do Brasil, porém é pouco discutida, o que leva ao desconhecimento dos profissionais de saúde e de grande parte da população. É necessário o entendimento sobre a forma pela qual o HTLV modifica a vida de seus soropositivos, para possibilitar o acesso à trajetória de procura, produção e administração do cuidado dessas pessoas e suas famílias e, consequentemente, fornecer dados para a elaboração de políticas públicas.

Estima-se que 15 a 20 milhões de pessoas no mundo estejam infectadas pelos subtipos mais prevalentes HTLV-I e/ou HTLV-II, entretanto a maioria dessas pessoas é assintomática. Os fatores genéticos e imunológicos são os principais responsáveis pelo aparecimento de doenças associadas. No Brasil, é possível afirmar que a infecção pelo HTLV constitui-se um problema de Saúde Pública, não sendo assumidas as devidas estratégias para o seu enfrentamento. Estudos de prevalência em grupos específicos confirmam a presença do HTLV em todo o país, com menor prevalência nos extremos Norte e Sul e maior no Sudeste e Nordeste, apontando índices maiores para o estado da Bahia ${ }^{(1)}$ com um agravo/doença de notificação compulsória, visto o crescente número de casos.
O HTLV é classificado como uma doença sexualmente transmissível. Consequentemente, apresenta formas de transmissão semelhantes às de outras doenças desse grupo, dentre elas, o vírus da imunodeficiência humana $(\mathrm{HIV})^{(2)}$. As pessoas com sorologia positiva mantêm uma rede de transmissão silenciosa pela via sexual, sanguínea e vertical. Os métodos sorológicos para diagnóstico da infecção podem ser classificados em duas categorias: os testes de triagem (testes imunoenzimáticos - ELISA) e os de confirmação (Westenblot ou immunoblot) ${ }^{(3)}$.

A problemática do viver com o HTLV é abrangente e complexa, pois interfere na vida cotidiana das pessoas soropositivas para o vírus, provocando mudanças profundas ${ }^{(2)}$. Essa problemática fundamenta-se na evidência de que as pessoas encontram diferentes maneiras de resolver problemas de saúde, sendo a escolha por determinado tratamento influenciada pelo contexto sociocultural.

O conceito de vulnerabilidade, além de incluir condicionantes tanto individuais quanto sociais, também engloba aspectos biológicos devido à peculiaridade do órgão genital feminino, diferente do masculino. A mucosa vaginal apresenta uma área maior de exposição ao sêmem do que o pênis ao fluido vaginal, isto é, a quantidade de 
vírus que pode ser transmitido do homem para a mulher é maior do que dessa para aquele.

Esse fator biológico, acrescido das relações desprotegidas em decorrência da dificuldade de negociação com o parceiro e o comportamento promíscuo desse, aumenta ainda mais as chances de essa mulher ser infectada pelo HTLV.

A importância de se discutir o contexto de vulnerabilidade, quando relacionado às relações de gênero, é fundamental para entender que a decisão sobre reprodução e contracepção é de corresponsabilidade entre homem e mulher, isto é, ambos devem manter um diálogo em que haja uma decisão conjunta sobre a prevenção ${ }^{(4)}$.

A utilização das ferramentas em saúde permite a identificação de fragilidades, vulnerabilidades, patologias prevalentes, funcionalidades da família acompanhada, além de expor, sobretudo, a identificação das causas da distância do cuidado oferecido pelo serviço de saúde. Essa detecção é importante para restaurar a confiança do usuário e reestabelecer o vínculo ${ }^{(5)}$.

A família tece redes envolvendo pessoas e relações próximas que possam garantir-lhe sustentabilidade e apoio na realização do próprio cuidado, bem como no alcance das condições e insumos necessários para realizá-lo. O emprego do genograma e do ecomapa, como ferramentas explicitadoras e analisadoras dessa experiência, torna visível e inteligível o modo de organização familiar para o cuidado, assim como a busca empreendida junto a serviços e profissionais de saúde, as respostas obtidas e sua efetividade ${ }^{(6)}$.

Dentro dessa perspectiva, propõe-se a realização deste estudo com o objetivo de descrever a dinâmica familiar de mulheres soropositivas para o HTLV.

\section{Método}

Estudo de caso exploratório, descritivo, de natureza qualitativa, realizado com três mulheres soropositivas para o HTLV cadastradas no Centro de Testagem e Aconselhamento (CTA) em um município do estado da Bahia no ano de 2017.

Neste estudo, dá-se ênfase ao modo como as mulheres soropositivas para o HTLV buscam cuidado e tratamento, considerando a influência dos fatores socioculturais, bem como individuais, que perpassam e determinam essas escolhas. Para a compreensão dos eventos delineados para a tal busca, foram utilizadas duas ferramentas que subsidiam o cuidado à saúde: o genograma e o ecomapa.

Os critérios de inclusão foram: pacientes do sexo feminino; confirmação do diagnóstico da sorologia para o HTLV I e/ou II; idade maior ou igual a 18 anos; serem cadastrados no Centro de Testagem e Aconselhamento-Serviço de Atendimento Especializado no Recôncavo Baiano, Brasil. O critério de exclusão foi mulheres cadastradas no CTA que não residissem na cidade lócus do estudo, por inviabilizar a entrevista na residência da cadastrada.

A coleta de dados deu-se por meio de consulta a 21 prontuários de mulheres soropositivas que realizavam acompanhamento no CTA, e aplicação de entrevista semiestruturada domiciliar. Os dados coletados subsidiaram a construção do Genograma e do Ecomapa. Os prontuários forneceram informações quanto ao cadastro, história clínica, logradouro e evolução clínica das cadastradas. Procedeu-se ao levantamento da Unidade de Saúde da Família (USF). Posteriormente, foi realizado o contato e a apresentação da pesquisa às enfermeiras das USF, seguida de agendamento e visita domiciliar acompanhada dos Agentes Comunitários de Saúde (ACS) de cada participante e a realização da entrevista no domicílio, mantendo o princípio da privacidade e do anonimato.

Após as entrevistas na residência dessas mulheres foi realizada a construção do genograma e ecomapa, tendo como participantes do estudo três mulheres que, após contato, incluíram-se nos critérios e aceitaram participar da pesquisa. As famílias foram designadas por nomes de flores (Violeta, Margarida e Jasmin), por se associarem com beleza, virtude, esperança e delicadeza. As mulheres e seus familiares foram identificados neste texto com as iniciais de seus nomes.

O genograma é um diagrama que delineia a estrutura e o histórico familiar e fornece informações sobre os vários papéis de seus membros e das diferentes gerações. Oferece bases para a discussão e análise das interações familiares. 
O ecomapa é o diagrama das relações entre a família e a comunidade, para ajudar na avaliação do apoio e suporte disponíveis e sua utilização pela família ${ }^{(7)}$.

Durante a construção do genograma e do ecomapa familiar, as participantes responderam, por meio de conversa previamente estruturada, informações sobre a sua origem, as particularidades dos seus membros familiares, os acontecimentos significativos de sua vida e as condições de saúde familiar.

O ecomapa familiar conectou as circunstâncias ao meio ambiente, mostrando o vínculo entre os membros da família e outros sistemas sociais. Também mostrou a relação entre família e comunidade: serviços da comunidade (creche, escola, unidade de saúde etc.); grupos sociais (igrejas, associação de moradores, grupos de atividades etc.); relações significativas (vizinhos, amigos, família etc.); trabalho; outros (formas de lazer).

Após análise do conteúdo dos dados empíricos levantados na entrevista semiestruturada, gravada e transcrita na íntegra, procedeu-se a confecção das ilustrações correspondentes ao genograma e ecomapa.
$\mathrm{Na}$ ilustração construída para o ecomapa familiar, o genograma com os membros da família e suas idades está apresentado no centro do círculo e os círculos externos mostram os contatos da família com a comunidade.

O estudo foi aprovado pelo Comitê de Ética em Pesquisa sob o Parecer n. 2.888.086 e respeitou os princípios éticos da pesquisa e foram adotadas as recomendações da Resolução n. 510, de 7 de abril de 2016, do Conselho Nacional de Saúde.

\section{Resultados}

A composição familiar está retratada no genograma. O sexo masculino foi representado por quadrados e o sexo feminino por círculos. Cada membro da família foi identificado pelas iniciais do nome (abaixo das formas geométricas), idade (dentro das formas geométricas) e ocupação (abaixo das iniciais dos nomes). Os dois traços paralelos colocados na parte superior direita de uma forma indicam falecimento e a causa da morte é informada abaixo das iniciais do nome.

Figura 1 - Genograma da Família Violeta



Fonte: Elaboração própria.

A família Violeta é composta por ela, N.B.J., 35 anos, autodeclara-se parda, soropositiva para HTLV há 3 anos, trabalha como serviços gerais em uma creche, com vínculo empregatício de servidora pública municipal, renda familiar de aproximadamente três salários mínimos, casada desde 2006 com E.B.J., 39 anos, alcoolista, motorista autônomo. Da união tiveram uma filha, I.B.J., de três anos. N.B.J. recebeu o diagnóstico na USF, durante o pré-natal de baixo risco. Reside em bairro periférico sem esgotamento sanitário. N.B.J. não possui irmãos e é filha única. Sente falta da presença do pai, que faleceu enquanto ainda era criança. Relata que sua morte 
não lhe traz tristeza, porque era muito pequena. Considera-se provedora da família, com o auxílio do esposo, e também cuidadora da família. Tem sua mãe como heroína e considera-se a ovelha negra da família, por possuir personalidade forte e, por vezes, gerar conflitos com os núcleos familiares. Relata que o marco mais importante de sua vida foi o nascimento de sua filha. A estrutura familiar é complementada pelos padrões de interação com a mãe e o marido: pelo casal (subsistema conjugal); entre o casal e a mãe, a qual refere presença e confidencialidade de todos os momentos de sua vida, inclusive do diagnóstico; e com a filha (subsistema fraternal).

Na narrativa, durante a entrevista, N.B.J. expressa dúvidas e medo acerca da soropositividade, principalmente quando recebeu o diagnóstico. Fala da expectativa pela chegada da filha, das transformações que perpassaram a gestação, das expectativas positivas, frustradas pela descoberta de uma patologia sexualmente transmissível, incurável, com repercussões nas relações interpessoais com o cônjuge/parceiro e com a criança. O processo de não amamentação repercutiu de forma negativa em sua vida enquanto mãe, e refere que faltou tal vínculo.
No Ecomapa da Família Violeta (Figura 2), a ausência de interação com outros membros da família é justificada, sobretudo pelo distanciamento geográfico e ausência de ligação desses com a família nuclear. Contudo, não representa uma relação de falta familiar para N.B.J., por caracterizar seus vínculos familiares com definições de união não conflituosa. Julga possuir vínculos fortes com a igreja católica, com a UBS, onde obteve o diagnóstico da soropositividade, com vizinhos, sua mãe, a escola de educação infantil onde trabalha e a creche em que a filha estuda. Considera o CTa um local de busca e manutenção da saúde, porém não se sente dependente do referido serviço de saúde, pois não considera o diagnóstico da soropositividade para o HTLV como algo que interfira em sua vida. Garante não possuir limitações de saúde que possam ser associadas ao diagnóstico. No Ecomapa, os traços representam as diferentes relações e buscam dar destaque à qualidade dos vínculos entre o paciente e os membros da família, com foco naqueles que vivenciam a condição crônica do HTLV.

Figura 2 - Ecomapa da Família Violeta

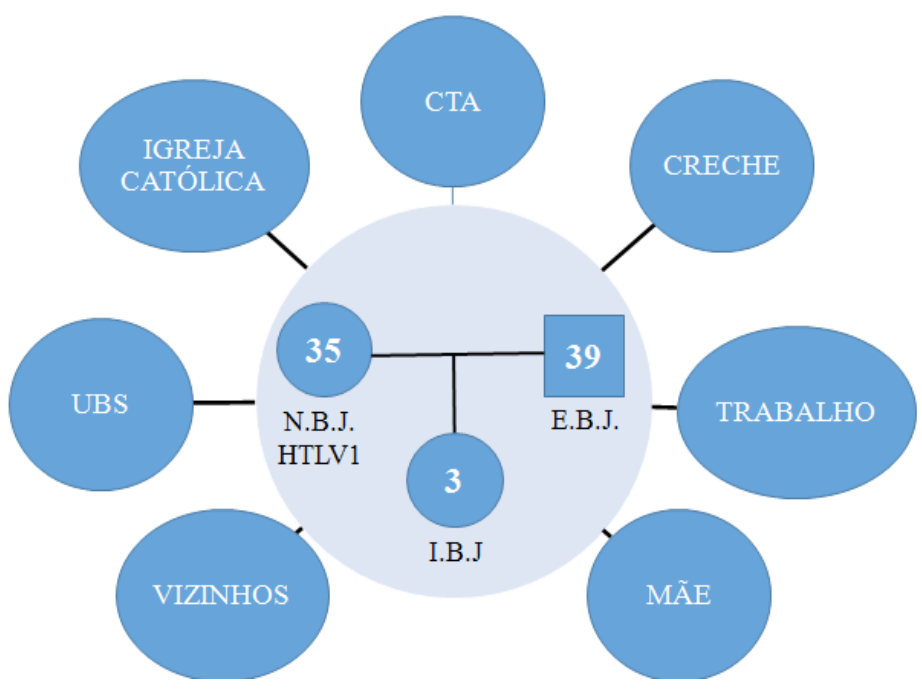

Fonte: Elaboração própria. 
A Família Margarida é composta por A.J.J., que se autodeclara preta, 19 anos, e seu filho G.J.J. de 1 ano e 3 meses, fruto de um namoro passageiro com um jovem de 23 anos. A.J.J. encara como um marco positivo ter tido o fruto dessa relação e por ter descoberto a soropositividade há um ano, quando realizava o pré-natal na rede básica de assistência. Não possui renda, reside em bairro periférico, sem sistema de esgotamento sanitário, com o filho e seus pais adotivos - J.A.M., hipertensa, servidora pública em uma instituição municipal, e T.B.M., aposentado por limitações físicas -, responsáveis pela manutenção financeira da casa. Possui três irmãs adotivas que não residem na casa da família. A.J.J., até os dois anos de idade, morou com a mãe biológica, depois foi adotada. Não possui contato com a família biológica e nem relação de afetividade. Refere aproximação e interação afetiva e de respeito com a família adotiva, que considera um núcleo familiar unido e acolhedor. Considera a mãe e a irmã adotiva mais nova como heroínas em sua vida, assim como intitula-se a ovelha negra da família, por ter engravidado jovem e descoberto a soropositividade nesse contexto. Não possui vínculo com o pai da criança, define o relacionamento como um namoro que só deixou de bom a criança, seu bem mais precioso. Não sabe informar se seu ex-parceiro realizou o teste para averiguar soropositividade para HTLV, mas acredita ter sido infectada pela mãe biológica na amamentação, que também não sabe informar se realizou testagem sorológica. O genograma familiar foi construído até a primeira geração, por se tratar de família adotiva, não possibilitando mecanismos de investigação da transmissão materno infantil.

Por se tratar de uma Infecção Sexualmente Transmissível, A.J.J. demonstrou, na entrevista, medo, incerteza, dúvidas e questionamentos sobre como adquiriu o HTLV e a forma de tratamento para a manutenção da sua qualidade de vida. Por ser um vírus ainda desconhecido por grande parte da população, a angústia e as incertezas aumentam pelo não reconhecimento de estudos e investimentos que coloquem a pessoa diagnosticada como prioridade destinada ao cuidado.

Figura 3 - Genograma da Família Margarida

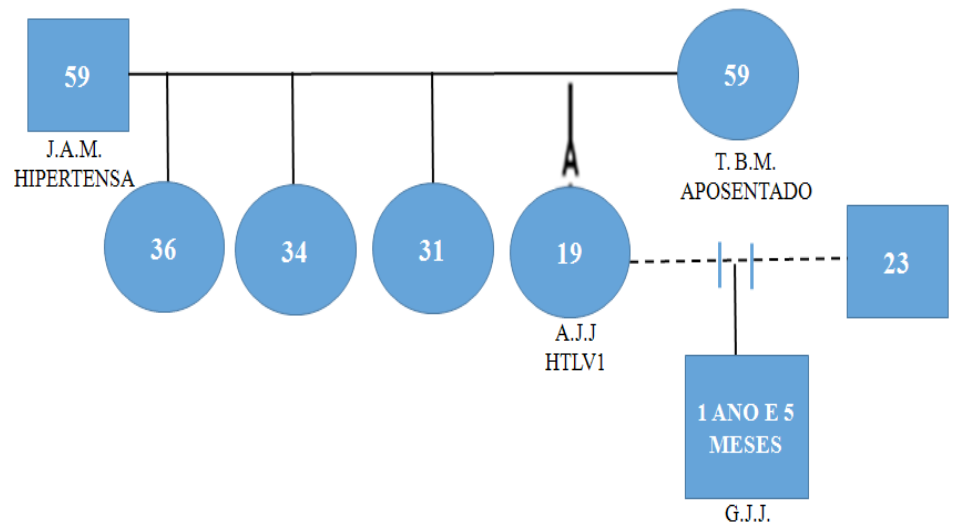

Fonte: Elaboração própria.

O Ecomapa da Família Margarida (Figura 4) revela que a descoberta da positividade, associada à gestação indesejada, ainda jovem, interferiu diretamente no convívio diário com a família adotiva, que a princípio não soube lidar com a situação. Possui vínculo fraco com a família biológica e com o CTA, visto como o lugar onde pegava as latas de leite para o filho, sem reconhecê-lo como um espaço de manutenção para a saúde. Possui vínculo forte com a família adotiva, UBS, igreja católica, escola técnica (onde faz o curso de técnico em Enfermagem), CTA e vizinhos. 
Figura 4 - Ecomapa da Família Margarida

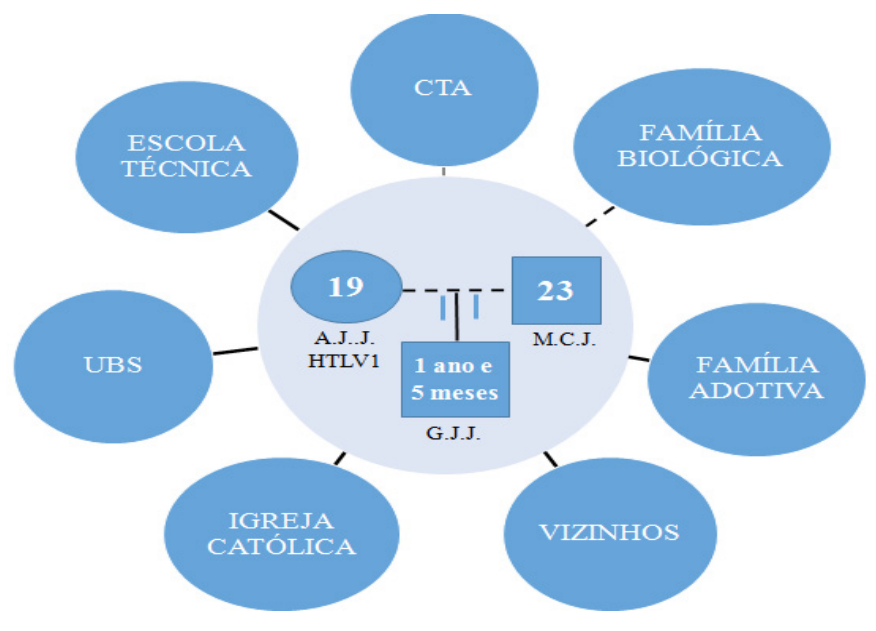

Fonte: Elaboração própria.

A Figura 5 descreve a Família Jasmin, composta por ela, E.S.J., sua genitora, um irmão e duas filhas. Autodeclara-se negra, com 35 anos, duas filhas (uma de cinco e outra de dois anos), autônoma, residente em bairro periférico, sem calçamento e saneamento básico; sua mãe, de 53 anos, é dona de casa; seu irmão, de 27 anos, comerciante. Afirma ter relação conflituosa com o pai das filhas que trabalha como garçom, 28 anos, mesmo não morando junto com ele. E.S.J. possui vínculo forte com o irmão e a mãe, com quem mora. Considera o irmão como provedor e cuidador da casa. Tem a mãe como a heróina de sua vida. Intitula-se a ovelha negra da família, por ainda ser parcialmente dependente do irmão e da mãe, que a auxiliam no cuidado e criação das suas duas filhas. O marco mais importante em sua vida foi o nascimento das filhas, que representam a força para trilhar seu caminho. A descoberta da soropositividade aconteceu há aproximadamente um ano, quando realizava o pré-natal da segunda filha na USF. Em seu discurso, E.S.J. afirma que, ao ser comunicada do diagnóstico pela equipe da USF, não conhecia as repercussões que o vírus traria à sua vida e chegou a confundir o dignóstico com o HIV, por conta da semelhança das siglas, recebendo posteriormente, em visita domiciliar realizada pela equipe de enfermagem, orientações sobre esse diagnóstico.

Figura 5 - Genograma da Família Jasmin

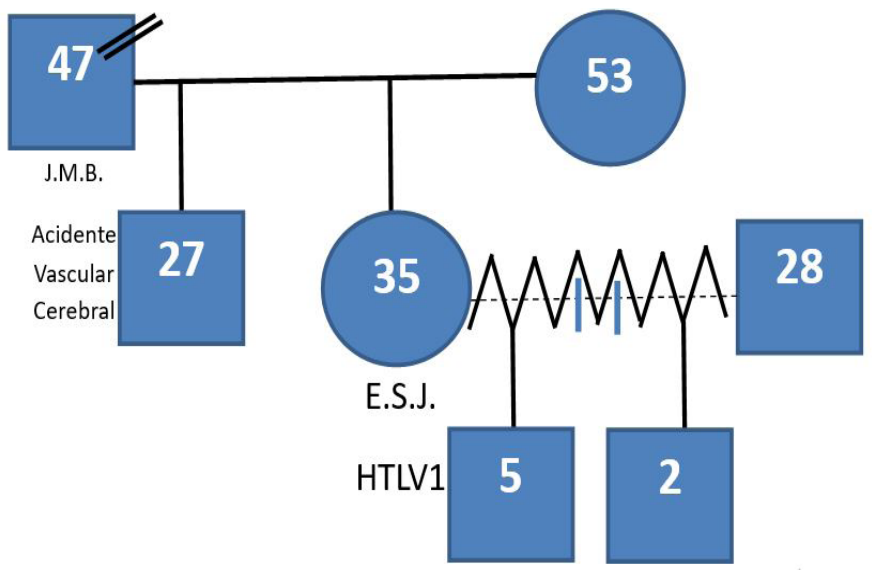


O Ecomapa da Família Jasmin representa a soropositividade como algo que não interfere em sua vida, por não possuir nenhum comprometimento em sua condição de saúde associada ao vírus. E.S.J. se vê como uma pessoa plenamente saudável e sem limitações associadas à soropositividade. Tem o seu núcleo familiar com a mãe, o irmão e as duas filhas como base, alicerce e sustentação para enfrentar os obstáculos da vida. Considera o CTA o espaço onde pega a fórmula láctea para a filha e refere não possuir necessidade de realizar acompanhamento de saúde, por se considerar saudável. Possui vínculos fortes com a UBS, família, vizinhos, e o local onde trabalha como garçonete e a creche onde as filhas estudam.

Figura 6 - Ecomapa da Família Jasmin

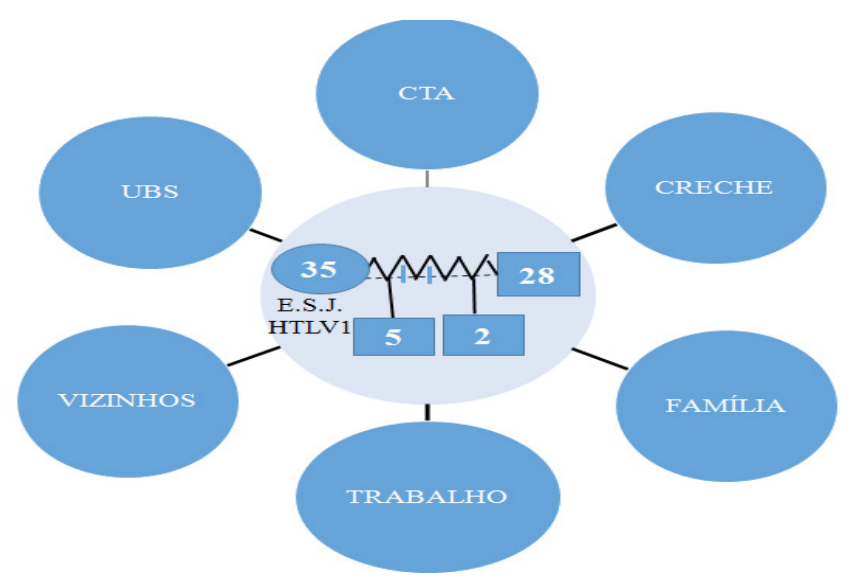

Fonte: Elaboração própria.

\section{Discussão}

A designação "condição crônica" abrange agravos de saúde não transmissíveis, transmissíveis persistentes, distúrbios mentais de longo prazo, deficiências físicas e estruturais contínuas. Tem como característica comum a persistência no tempo, podendo manter-se por vários anos ou décadas, com a necessidade de cuidados constantes $^{(2)}$.

As representações gráficas do genograma e ecomapa têm sido muito úteis, pois privilegiam a abordagem da vivência da condição crônica, que requer gerenciamento continuado das pessoas, da família, dos serviços e de profissionais de saúde.

As redes para o cuidado em saúde, tecidas pelo indivíduo e suas famílias, dão sustentação e apoio na experiência de adoecimento e cuidado. No caso deste estudo, essa rede foi ilustrada pelo genograma e ecomapa. O primeiro representa a família consanguínea de parentesco e/ou afetividade, descrevendo sua composição, qualidade de seus vínculos e os núcleos cuidadores. O ecomapa evidencia os recursos disponíveis e acessados pela família, a qualidade de seus vínculos e relações.

\footnotetext{
Tais redes vão sofrendo modificações ao longo do tempo e espaço, o que lhes confere configurações próprias e dinamicidade. Contudo, não é tarefa fácil dar visibilidade às modificações sofridas pelas famílias e suas redes ao longo da experiência de adoecimento, dada a limitação da representação gráfica no formato de desenho plano, como tem sido até então utilizado, por mostrar apenas um "instantâneo do momento familiar, ${ }^{(7: 657)}$.
}

A análise do material empírico revelou pontos de convergência fortes entre as participantes do estudo: a descoberta da soropositividade ocorreu no pré-natal em USF; as relações fracas com o CTA, pelo fato de não o visualizarem como espaço de busca e manutenção da saúde, somente frequentado nos momentos de testagem sorológica, confirmação diagnóstica e suporte para a distribuição de fórmula láctea; a autodefinição de "ovelha negra" por terem adquirido uma patologia sexualmente 
transmissível e por questões de relações interpessoais com a família. Além disso, por permanecerem assintomáticas, as participantes negligenciavam sua condição de soropositividade e omitiam ações de cuidado, por acreditarem que não desenvolverão as patologias associadas ao HTLV.

A negligência do cuidado decorre do fato de o HTLV ser um vírus com longo período de latência, cursando de forma assintomática para o maior número de soropositivos, e por não possuir alto perfil de morbimortalidade ${ }^{(1)}$. Uma vez diagnosticado o HTLV, a primeira questão é a necessidade de tornar visível em quais sujeitos o vírus encontra-se presente, pois toda a gama de consequências para as suas vidas não se reduzem ao problema da saúde em si, mas igualmente aos seus próprios modos e projetos de vida, dadas as características epidemiológicas de transmissão do vírus e suas possibilidades de tratamento e prevenção da infecção ${ }^{(8)}$.

Em contrapartida, evidenciando a vulnerabilidade individual, as soropositivas não possuem informações precisas sobre o diagnóstico. As profissionais de saúde possuem informações científicas reduzidas sobre o vírus, pois geralmente são de difícil acesso. A insegurança e o medo são sentimentos presentes no momento de oferecer esclarecimentos sobre a infecção a um soropositivo ${ }^{(2)}$.

Em relação ao HTLV-I, a problemática da identificação de pessoas infectadas na rede familiar é crucial. Nesses casos, é necessário considerar ações de prevenção secundária quanto ao risco de transmissão vertical do vírus (especialmente durante a amamentação). Tais questões são desafios que as políticas públicas deveriam cuidadosamente enfrentar $^{(8)}$.

É importante a identificação/triagem de todas as gestantes durante o pré-natal e o desenvolvimento de ações para a prevenção da transmissão vertical, como a orientação para a não amamentação e disponibilização de fórmula infantil para alimentar a criança. Entretanto, ainda não se criou política específica para essas mães e crianças ${ }^{(2)}$.
As redes para o cuidado em saúde são compostas pelos desenhos do genograma e do ecomapa que, por sua vez, foram empregados como ferramentas de ordenação e análise, ao abordar a experiência do adoecimento e do cuidado familiar. Dessa forma, esses desenhos evidenciam o modo como as pessoas tecem redes de sustentação e apoio para o cuidado, das quais podem participar os serviços, por meio dos vínculos estabelecidos com seus profissionais. Estes podem dar certo apoio para o cuidado realizado prioritariamente pela própria família ${ }^{(9)}$.

Nesse sentido, tornam-se relevantes as considerações acerca do modo de assistência atual oferecida às pessoas acometidas pelo HTLV, o lugar do paciente como sujeito, assim como implicações relacionadas às questões de vida, dentre outros aspectos.

O conhecimento da trajetória na busca por serviços de saúde permite analisar as facilidades, dificuldades e limitações de pessoas e famílias em relação ao acesso a cada nível de atenção e àquilo que the foi oferecido, além do modo como os serviços de saúde deram respostas aos problemas dessas pessoas $^{(9)}$.

Sendo assim, requer desenvolvimento de práticas, de habilidades adquiridas ao longo dos processos de envolvimento dos atores em seus contextos específicos. Assim, as hesitações, as incertezas, as perplexidades, as formações e dissoluções de laços interativos são elementos que devem ser devidamente levados em consideração ${ }^{(10)}$.

As trajetórias empreendidas pelo indivíduo e suas famílias configuram a construção de desenho no qual é possível observar quais serviços foram acessados e a sequência das buscas, o que evidencia o número de instituições e seu nível de atenção para o atendimento das necessidades de saúde demandadas, dando uma noção do alcance e da integralidade. A percepção do paciente sobre o sintoma e seu significado é parte de sua experiência de enfermidade, e o itinerário terapêutico é a construção social da doença; assim, o significado da doença emerge nesse processo ${ }^{(11)}$. 
Pode-se afirmar também que o serviço especializado necessita de reorganização estrutural e de atendimento, que pense na possibilidade de acolhimento, formação de grupos educativos e ainda a participação de outros profissionais implicados e envolvidos no acompanhamento $^{(12)}$ das mulheres com HTLV, de modo a oferecer uma atenção qualificada.

Nesta pesquisa, o genograma e o ecomapa permitiram ainda melhor visualização das trocas estabelecidas, da lógica empreendida pelos indivíduos e suas famílias no cuidado em saúde, além de terem favorecido o entendimento das múltiplas implicações do adoecimento para a vida, evidenciado nos núcleos de cuidado no genograma. Este permite a visualização da composição familiar e, nela, das relações que são estabelecidas entre seus entes, os núcleos de cuidado. Entretanto, não possibilita evidenciar os demais participantes desse cuidado e que o fazem em diferentes momentos e de diversos modos. O ecomapa é utilizado como forma de dar visibilidade a tais redes ${ }^{(6)}$.

O estudo revelou que, quando se confirmam diagnósticos de soropositividade para o HTLV, a visualização dos núcleos familiares para possível identificação de transmissão vertical não acontece pelo profissional enfermeiro que acompanha a gestante na Estratégia Saúde da Família, impossibilitando à equipe multiprofissional possíveis intervenções.

Devido à área de abrangência, seria difícil a confecção de genograma e ecomapa pelos profissionais de saúde para todas as famílias da área da ESF. No entanto, a construção de genograma e ecomapa na ESF vislumbra o paciente como um ser singular, ligado a um núcleo familiar, ao ambiente e à comunidade em que vive. Muito frequentemente, as relações repetem-se com o passar das gerações e estão intimamente ligadas ao processo saúde-doença ${ }^{(13)}$.

No caso deste estudo, a aplicação do genograma permitiu a visualização do processo de adoecer, facilitando melhor compreensão do sentido do HTLV para as mulheres participantes. Ao avaliar cuidadosamente o genograma e o ecomapa foi possível ter um olhar histórico de como a família enfrenta(ou) os acontecimentos críticos.

O aumento do número dos casos de mulheres infectadas é decorrente de fatores que vão desde os problemas do sistema de saúde, com acesso precário, falta de orientações por parte dos profissionais da área, até aos determinantes socioeconômicos, políticos e culturais, os quais influenciam na educação e no conhecimento dessa parte da população quanto aos programas e métodos preventivos de Infecções Sexualmente Transmissíveis (IST). O processo crescente de mulheres portadoras do vírus HTLV traz agravos também à saúde, tanto dos seus parceiros quanto de seus filhos. No caso destes, pela transmissão vertical durante a gravidez e a amamentação.

Destaca-se a possibilidade do emprego de genograma e ecomapa por profissionais de saúde, em especial pelo enfermeiro, permitindo-lhes conhecer o modo como a família organiza-se para o cuidado, os recursos e as redes com que contam para sustentá-la e ampará-la na experiência de adoecimento crônico. Desse modo, conseguem visualizar quando seus potenciais de cuidado precisam ser renovados.

Constituiram-se limitações no desenvolvimento da pesquisa, a dificuldade de acesso às residências das mulheres, pelo quantitativo das participantes incluídas no estudo, e a falta de pesquisas anteriores sobre o tema.

\section{Conclusão}

O estudo revelou que as participantes possuíam pontos de convergência forte: descoberta da soropositividade no pré-natal em USF; estabeleciam relações fracas com o CTA, por não o visualizarem como espaço de busca e manutenção da saúde; autodefinição como "ovelha negra da família”, por terem adquirido uma patologia sexualmente transmissível; questões de relações interpessoais com a família; negação da condição de soropositividade; e omissão quanto às ações de cuidado.

A construção e a descrição da dinâmica familiar baseadas no genograma e ecomapa 
possibilitaram a exposição sobre o modo de vida das mulheres com HTLV. Também evidenciaram que os serviços e profissionais de saúde devem ser sensibilizados sobre o adoecimento crônico pelo HTLV. A enfermagem deve estar inserida na produção do conhecimento sobre essa temática, uma vez que representa uma área que contempla, no seu objeto, o cuidar. O conhecimento dos enfermeiros sobre essa problemática poderá redirecionar ou reconduzir as ações preventivas focadas na Saúde Pública e na assistência.

Destaca-se a possibilidade de emprego do genograma e do ecomapa por profissionais de saúde, em especial pelo enfermeiro, permitindo-lhes conhecer o modo como a família organiza-se para o cuidado, os recursos e as redes com que conta para sustentá-la e ampará-la na experiência de adoecimento.

\section{Colaborações:}

1 - concepção, projeto, análise e interpretação dos dados: Elaine de Araújo Dias e Maria da Conceição Costa Rivemales;

2 - redação do artigo e revisão crítica relevante do conteúdo intelectual: Elaine de Araújo Dias, Maria da Conceição Costa Rivemales, Lavinya Lima Cordeiro Oliveira, Daniela Carneiro Sampaio, Claudia Feio de Maia Lima e George Mariane Soares;

3 - aprovação final da versão a ser publicada: Elaine de Araújo Dias e Maria da Conceição Costa Rivemales.

\section{Referências}

1. Pereira WA, Mesquita EM. Vírus linfotrópico de células T humana (HTLV): doenças associadas e dificuldades no diagnóstico e tratamento. Rev Ciênc Saúde [Internet]. 2015 [cited 2017 Nov 28];17(1):40-6. Available from: http://www. periodicoseletronicos.ufma.br/index.php/ rcisaude/article/view/4659

2. Santos ACC, Soares DJ, Rivemales MCC. (Un)Familiarity, illness and limitations imposed by HTLV: experiences of HIV positive women. Cad saúde colet. 2017;25(1):45-50. DOI: $10.1590 / 1414-462 \times 201700010186$
3. Carneiro-Proietti AB, Amaranto-Damasio MS, Leal-Horiguchi CF, Bastos RHC, Seabra-Freitas G, Borowiak DR, et al. Mother-to-Child Transmission of Human T-Cell Lymphotropic Viruses-1/2: What We Know, and What Are the Gaps in Understanding and Preventing This Route of Infection. J Pediatric Infect Dis Soc. 2014;3(Suppl 1)S24-S29. DOI: $10.1093 /$ jpids/piu070

4. Sousa MCP, Espírito Santo ACG, Motta SKA. Gênero, vulnerabilidade das mulheres ao HIV/Aids e ações de prevenção em bairro da periferia de Teresina, Piauí, Brasil. Saúde soc. 2008;17(2):58-68. DOI: 10.1590/S0104-12902008000200007

5. Nogueira APF, Lucena KDT, Pinto BPV, Araújo MF, Ataíde MCC, Pedrosa Neto WD, et al. The importance of using genograms for understanding of family dynamics. J Nursing UFPE on line, 2017 Dec;11(12):5110-5. DOI: 10.5205/1981-8963-v11i1 2a23522p5110-5115-2017

6. Souza IP, Bellato R, Araújo LFS, Almeida KBB. Genogram and eco-map as tools for understanding family care in chronic illness of the young. Texto Contexto Enferm. 2016;25(4):e1530015. DOI: 10.1590/0104-07072016001530015

7. Musquim C, Araújo L, Bellato R, Dolina J. Genograma e ecomapa: desenhando itinerários terapêuticos de família em condição crônica. REE. 2013;15(3):654-64. DOI: 10.5216/ree.v15i3.17730

8. Zihlmann KF, Mazzaia MC, Alvarenga AT. Sentidos da interrupção da amamentação devido infeção pelo vírus linfotrópico de células $\mathrm{T}$ humanas do tipo 1 (HTLV-1). Acta paul enferm. 2017;30(1):80-6. DOI:10.1590/1982-0194201700012

9. Bellato R, Araújo LFS, Dolina JV, Musquim CA, Corrêa GHLST. Experiência familiar de cuidado na situação crônica. Rev esc enferm USP. 2016;50(spe): 81-8. DOI: 10.1590/S0080-623420160000300012

10. Alves PC. Itinerário terapêutico e os nexus de significados da doença. Rev Ciência Soc [Internet]. 2015 [cited 2017 Aug 24];1(42):29-43. Available from: http://www.periodicos.ufpb.br/ojs/index. php/politicaetrabalho/article/view/23308

11. Roberti Junior JP, Benetti IC, Zanella M. Itinerário terapêutico, escolha e avaliação de tratamento para problemas de saúde. Cad Bras Saúde Ment [Internet]. 2017 [cited 2017 Jul 19];8(18). Available from: http://incubadora.periodicos.ufsc.br/index. $\mathrm{php} / \mathrm{cbsm} /$ article/view/4424 
12. Barreto JAPS, Marinho MNASB, Vidal ECF, Pinto AGA, Aquino PS, Vidal ECF. Feelings of women with human papilloma virus regarding their infection: an exploratory study. Online Braz J Nurs. 2016;15(3):382-92. DOI: 10.17665/ $1676-4285.20165305$

13. Borges CD, Costa MM, Faria JG. Genograma e atenção básica à saúde: em busca da integralidade. Rev Psicol Saúde [Internet]. 2015 [cited 2018 Jan 12];7(2):133-41. Available from: http://pepsic.bvsalud.org/scielo.php?script=sci_ arttext\&pid=S2177-093X2015000200007\&lng=es

Recebido: 27 de setembro de 2019

Aprovado: 9 de dezembro de 2019

Publicado: 11 de março de 2020

A Revista Baiana de Enfermagem utiliza a Licença Creative Commons - Atribuição-NãoComercial 4.0 Internacional. https://creativecommons.org/licenses/by-nc/4.0/ Este artigo é de acesso aberto distribuído sob os termos da Licença Creative Commons (CC BY-NC). Esta licença permite que outros remixem, adaptem e criem a partir do seu trabalho para fins não comerciais. Embora os novos trabalhos tenham de lhe atribuir o devido crédito e não possam ser usados para fins comerciais, os usuários não têm de licenciar esses trabalhos derivados sob os mesmos termos. 